\title{
Increased Innate T cells Frequencies In Infants And School-age Children With Neonatal Encephalopathy
}

\author{
Nawal Abdullah Taher ${ }^{1}$, Alhanouf alharbi ${ }^{1}$, Mary O’Dea ${ }^{2,3,4}$, Tammy Strickland 2, Zunera Zareen ${ }^{2,3}$, \\ Eleanor J Molloy,3,4,5, Derek G. Doherty'. \\ ${ }^{1}$ Immunology and 2 Paediatrics, School of Medicine, Trinity College Dublin; TTMI, ${ }^{3}$ Paediatrics, \\ Tallaght University Hospital, Dublin; 'Paediatrics, Coombe Women's and Infants' University \\ Hospital, Dublin; ${ }^{5}$ Neonatology, Our Lady's Children's Hospital, Crumlin, Dublin 12, Ireland.
}

\section{Introduction}

Neonatal encephalopathy (NE) is the leading cause of neurodevelopmental delay, epilepsy and cerebral palsy with a prevalence of 1-3 per 1,000 live births. Epidemiological and experimental evidence suggests that pre-existing intrauterine infection and inflammation, involving neutrophils and monocytes, are implicated in brain injury and subsequent cerebral palsy $(1,2)$. Lymphocytes of the innate and adaptive immune systems play important roles in early immunity against infection and in inflammation (3). They can control the responses of monocytes and neutrophils and offer potential targets for therapeutic intervention. The aim of this study was to measure the frequencies of innate and adaptive lymphocytes, including subsets of T cells, B cells and natural killer (NK) cells in neonates and school-age children with NE and in agematched controls.

\section{Methods}

Whole blood from neonates with NE $(n=22)$ and neonatal controls $(n=14)$ and school-age children with NE $(n=19)$ and age-matched controls $(n=23)$ subjects was stained with monoclonal antibodies specific for lymphocyte surface markers and analysed by flow cytometry. The frequencies of CD4+, CD8+, CD4-CD8- (double negative or DN) and CD4+CD8+ double positive (DP) T cells (CD3+), B cells (CD19+), NK cells (CD3-CD56+) invariant natural killer T cells (iNKT cells; CD3+Va24Ja18+), mucosal-associated invariant T (MAIT) cells (CD3+CD8+CD161+Va7.2+) and the Vס1+, Vס2+ and Vठ3+ subsets of gamma/delta $(\mathrm{\gamma} \delta) \mathrm{T}$ cells were compared between the NE and control groups.

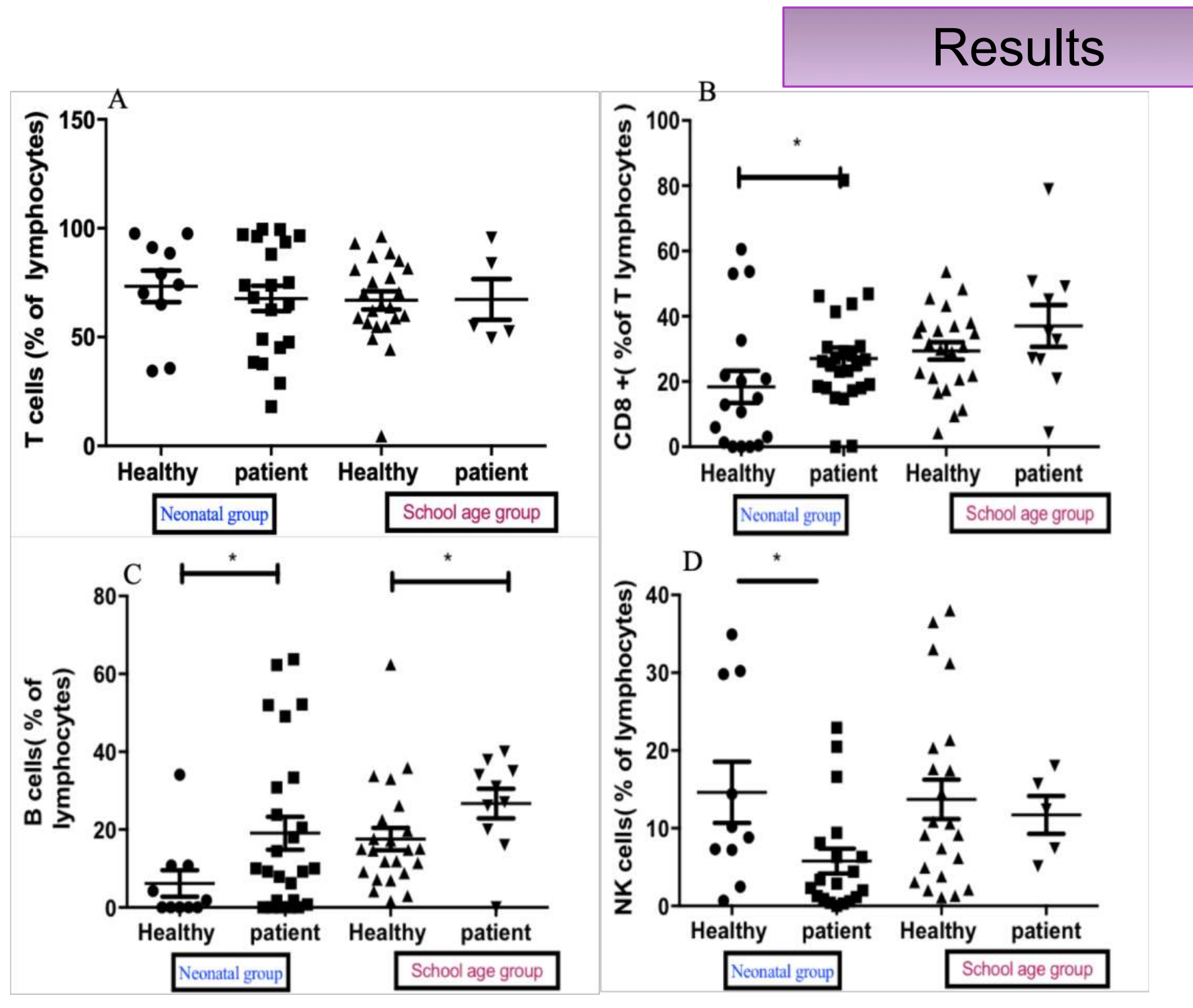

Figure 1. Lymphocyte frequencies in neonates and school-age children with NE. Frequencies of $T$ cells $(A)$, $\mathrm{CD}^{+}$cells as percentages of total T cells $(B)$, B cells $(C)$, and NK cells (D) as percentages of total lymphocytes in neonates and school-age children with NE and agematched control subjects. ${ }^{*} P<0.01$

\section{References}

1. Azzopardi et al. N Engl J Med 2014; 371: 140-149.

2. Jenster et al. Ped Res 2014; 76: 93-99.

3. Godfrey et al. Nat Immunol 2015; 16: 1114-1123.[-

\section{Conclusion}

Our findings suggest that $\mathrm{CD} 8^{+} \mathrm{T}$ cells and $\mathrm{B}$ cells are involved in immune responses that lead to NE and that NK cells may be depleted. Our results do not suggest a role for innate T cells, including iNKT cells, MAIT cells or $\mathrm{\gamma} \delta$ in the pathogenesis. These findings provide new insights into the pathogenesis of neonatal brain injury and its associated sequelae, such as cerebral palsy, and suggest that immunotherapeutic interventions may improve these neurologic disabilities in childhood. 